\title{
Epidemiological Profile of Intestinal Obstructions in Koutiala, Mali: About 65 Cases
}

\author{
Mahamadou Coulibaly1,2*, Drissa Traoré1,3, Birama Togola ${ }^{1,3}$, Souleymane Sanogo ${ }^{3}$, \\ Bréhima Bengaly1,3, Drissa Ouattara ${ }^{3}$, Siaka Diallo ${ }^{3}$, Madiassa Konaté ${ }^{1,4}$, Nouhoum Ongoiba ${ }^{1,3}$
}

\author{
${ }^{1}$ Faculty of Medicine, University of Science, Technique and Technologies of Bamako, Bamako, Mali \\ ${ }^{2}$ Department of Surgery, Koutiala Hospital, Bamako, Mali \\ ${ }^{3}$ Department of Surgery, University Hospital Center Point G, Bamako, Mali \\ ${ }^{4}$ Department of General Surgery, CHU Gabriel Touré, Bamako, Mali \\ Email: *cmahamadou38@yahoo.fr
}

How to cite this paper: Coulibaly, M., Traoré, D., Togola, B., Sanogo, S., Bengaly, B., Ouattara, D., Diallo, S., Konaté, M. and Ongoiba, N. (2020) Epidemiological Profile of Intestinal Obstructions in Koutiala, Mali: About 65 Cases. Surgical Science, 11, 117-121. https://doi.org/10.4236/ss.2020.116015

Received: May 16, 2020

Accepted: June 9, 2020

Published: June 12, 2020

Copyright (c) 2020 by author(s) and Scientific Research Publishing Inc. This work is licensed under the Creative Commons Attribution International License (CC BY 4.0).

http://creativecommons.org/licenses/by/4.0/

\begin{abstract}
Aim: To assess the epidemiological profile of intestinal obstructions at the Koutiala district hospital. Patients and Method: This was a prospective and descriptive study taking place from August 1, 2017 to April 30, 2020. The files of patients with acute intestinal obstruction in the general surgery department of the Koutiala district hospital were collected. In this study, patients operated on for acute intestinal obstruction were included. Non-operated patients were not included in the study. Result: The records of 65 patients operated on for acute intestinal obstruction were collected. The mean age was $32 \pm 22$ with extremes of 1 year and 94 years. 7 infants (10.8\%) and 1 4-year-old child (1.5\%) were identified. The 16 to 59 age group was more common. Males were the majority with $70.8 \%(\mathrm{n}=46)$. The sex ratio was 2.4 . The rate of bowel obstruction in the general population in the circle was 8.1 cases per 100,000 population. According to provenance, patients came from inside the circle (rural areas) in $87.7 \%$ of the cases $(n=57)$ and from the city of Koutiala in $12.3 \%(n=8) .33 .9 \%$ of our patients had undergone laparotomy (n $=22$ ). Patients consulted urgently in $93.8 \%$. The etiologies are dominated by post-operative straps (33.8\%) and volvulus (24.6\%). We noted 12 cases of intestinal necrosis. Postoperative morbidity was $13.8 \%$ of cases $(n=9)$ and mortality of $6.1 \%$ of cases $(n=4)$. Conclusion: Bowel obstruction is one of the most frequent surgical emergencies in our circle. They most often affect young subjects and young adult males. The etiologies are dominated by the post-operative flanges. Complications remain elevated.
\end{abstract}

\section{Keywords}

Epidemiology, Intestinal Obstruction, Koutiala 


\section{Introduction}

Acute bowel obstruction is characterized by a complete and persistent cessation of the transit of materials and gases through any segment of the digestive tract. It is one of the main causes of acute abdominal emergencies. In Dakar, Soumah brought in 4 years, 202 cases and in Niger, Harouna brought in 18 months 124 cases [1] [2]. It is a disease that is seen most often in adult males [2]. Mortality linked to intestinal obstruction is high, varying from $6 \%$ to $20 \%$ [1] [3]. The aim of the present study was to assess the epidemiological profile of patients with intestinal obstruction at the Koutiala district hospital.

\section{Methodology}

This was a prospective and descriptive study from August 1, 2017 to April 30, 2020. The records of patients with acute bowel obstruction in the general surgery department of Koutiala District Hospital were collected. In this study, patients operated on for acute intestinal obstruction were included. Non-operated patients were not included in the study. The comparison test was the Chi-square test and the probability $\mathrm{p}<0.05$ was considered significant. The realization of this work required a detailed database which was validated by our scientific staff, we used for that the medical file of the patients, the consultation register, the notebooks of the operative report. The parameters studied were frequency, sex, age, incidence rate, geographic origin, duration of development, contributing factors, etiologies, morbidity and mortality.

\section{Result}

The files of 65 patients operated on for acute intestinal obstruction were collected. These occlusions represented $1.1 \%$ of consultations $(n=5657), 6.2 \%$ of surgical procedures $(n=1050)$ and $21.7 \%$ of acute surgical abdomens $(n=299)$. They were the second cause of abdominal surgical emergencies after peritonitis $(40.5 \%, \mathrm{n}=121)$ and before acute appendicitis $(21.1 \%, \mathrm{n}=63)$. The mean age was $32 \pm 22$ with extremes of 1 year and 94 years. 7 infants (10.8\%) and 1 4 -year-old child (1.5\%) were identified. The 16 to 59 age group was more frequent with $64.6 \%$ of the cases (Table 1). Males were the majority with $70.8 \%$ (n $=46$ ). The sex ratio was 2.4 (Table 2). The rate of bowel obstruction in the

Table 1. Distribution of patients operated on for acute intestinal obstruction in Koutiala from August 1, 2017 to March 31, 2020 according to age group.

\begin{tabular}{ccccccc}
\hline Slices & Male & $\%$ & Female & $\%$ & Number of cases & $\%$ \\
\hline 0 - 5 years & 6 & 13 & 2 & 10.5 & 8 & 12.3 \\
6 - 15 years & 4 & 8.7 & 4 & 21.1 & 8 & 12.3 \\
16 - 59 years & 29 & 63 & 13 & 68.4 & 42 & 64.6 \\
$>60$ years & 7 & 15.2 & & & 7 & 10.8 \\
Total & 46 & 70.8 & 19 & 29.2 & 65 & 100 \\
\hline
\end{tabular}


Table 2. Distribution of patients operated on for acute intestinal obstruction in Koutiala from August 1, 2017 to March 31, 2020 according to etiologies and sex.

\begin{tabular}{ccccc}
\hline Etiologies & Male & Female & Number of cases & $\%$ \\
\hline Primitive flanges & 1 & 1 & 2 & 3.1 \\
Post-operative flanges & 11 & 11 & 22 & 33.8 \\
Strangled parietal hernia & 9 & 4 & 13 & 20 \\
Strangulated internal hernia & 4 & 0 & 4 & 6.2 \\
Acute intestinal invagination & 6 & 1 & 7 & 10.8 \\
Volvulus & 14 & 2 & 16 & 24.6 \\
Stenosing intestinal tumor & 1 & 0 & 1 & 1.5 \\
Total & 46 & 19 & 65 & 100 \\
\hline
\end{tabular}

general population in the circle was 8.1 cases per 100,000 population. In the 0 to 5 year old population, 4.9 cases per 100,000 inhabitants were identified. According to provenance, patients came from inside the circle (rural areas) in $87.7 \%$ of the cases $(n=57)$ and from the city of Koutiala in $12.3 \%(n=8) .33 .9 \%$ of our patients had a history of laparotomy $(\mathrm{n}=22)$. The occlusions were favored by intense physical activities (farmers, breeders, workers, housewives) in $69.2 \%$ of the cases $(\mathrm{n}=45)$. We also noted medical factors (dysuria, constipation) in 40 patients (61.5\%). Emergency consultations represented $93.8 \%$ of cases $(n=61)$. The median duration of bowel obstruction was $3 \pm 6.3$ days with extremes of 1 and 30 days. The strangulation mechanism made up $98.5 \%$ of cases $(n=64)$ including postoperative bridles $(33.8 \%, \mathrm{n}=22)$, strangulated hernias $(26.2 \%, \mathrm{n}=17)$ and volvulus $(24.6 \%, \mathrm{n}=16)$ (Table 2$)$. We noted 12 cases of intestinal necrosis or $18.5 \%$ of the cases. Bowel obstruction was associated with malaria in 4 patients (6.1\%), high blood pressure in 3 patients (4.6\%) and diabetes in 2 patients (3.1\%). Postoperative morbidity was $13.8 \%$ of cases $(n=9)$. These were 4 cases of parietal suppuration, 2 cases of anastomotic release, 2 cases of external digestive fistula and 1 case of peri-stomal ulceration. Mortality was $6.1 \%$ of cases $(\mathrm{n}=$ 4). The average length of hospital stay was 5.18 days \pm 2.66 ( 2 - 17 days).

\section{Discussion}

Acute intestinal obstructions are frequent in our department, it is the second cause of acute surgical abdomen after acute peritonitis as reported by the authors [3] [4]. They can appear at all ages. In Africa, it is young people and young adults who are most affected with an average age between 28 and 40 years [2] [4]. This would be linked to the strangulation mechanism whose rate is high in this population. On the other hand in Western countries, intestinal obstructions generally occur after an obstruction or a digestive compression by tumor and which are seen much more in elderly subjects [5]. Our study also brings some cases in infants and small children who were secondary to an acute intestinal intussusception as evidenced by the study of Arnaud [6]; and in this population 
(0 - 5 years), the incidence of bowel obstruction was 4.9 cases per 100,000 population. This rate is much lower than those reported by Westerners who included between 20 and 38 cases per 100,000 inhabitants [6] [7]. This rate certainly does not reflect the real incidence of intestinal obstructions in this age group in the circle because of the under medicalization of the circle but also by the presence in the circle of other health structures which take care of occlusions intestinal. Sex is not a risk factor for the occurrence of intestinal obstruction, but the predominance of men is clear in the literature [2] [4] [8]. Concerning the strangulation mechanisms, the postoperative flanges were the majority; this would be justified by a considerable number of previous laparotomies (33.9\%). This notion of anterior laparotomy is provided by several authors with a rate varying between $43 \%$ and $66 \%$ [1] [9].

We noted an evolution of the disease beyond 5 days in $26.2 \%$ of the patients. Bowel obstruction may have been mistaken for malaria syndrome or salmonellosis. This long delay could be explained by self-medication in our context and by the geographical situation because $87.7 \%$ of our patients came from inside the circle and some of them would travel more than 100 kilometers before arriving at the hospital. hospital; and this delay in consultation would be the basis of the high number of intestinal necrosis which was $18.5 \%$ and post-operative morbidity of $13.8 \%$. This morbidity explains the average hospital stay of 5.18 days in these patients, which can reach up to 17 days. The same observation is made by Dembélé [4]. We also found that age is a factor influencing mortality because among the 4 patients who died, 3 had an age greater than or equal to 60 years. During this study, we were confronted by a certain amount of limitation, namely the lack of financial means of the patients, the insufficiency of technical platform and the lack of qualified personnel.

\section{Conclusion}

Bowel obstruction is one of the most common surgical emergencies in our circle. They most often affect young subjects and young adult males. The etiologies are dominated by the post-operative flanges. Complications remain elevated.

\section{Conflicts of Interest}

The authors declare no conflicts of interest regarding the publication of this paper.

\section{References}

[1] Soumah, S.A., Ba, P.A., Diop, P.S., Ka, O. and Touré, C.T. (2013) L'occlusion intestinale par brides: aspects étiologiques, cliniques et thérapeutiques à propos de 123 . RECAC, 1, 14-17.

[2] Harouna, Y., Haya, H., Abarchi, H., Rakoto Malala, J., Gazi, M., Seibou, A., Abdou, I., Moussa, M. and Bazira, I. (2000) Les occlusions intestinales: principales causes et morbi-mortalité à l'hôpital national de Niamey Niger, étude prospective à propos de 124 cas. Médecine d'Afrique Noire, 47, 205-207. 
[3] Harissou, A., Ibrahim, A., Oumarou, H., Amadou, M., Halidou, M., Mansour, A. and Yacouba, H. (2016) Etiologies et pronostic des occlusions intestinales aigues mécaniques à l'Hôpital National de Zinder: étude transversale sur 171 patients. Pan African Medical Journal, 24, 248. https://doi.org/10.11604/pamj.2016.24.248.8372

[4] Dembele, B.T., Traore, A., Diakite, I., Kante, L., Togo, A., Maiga, A., Diarra, M.B., Coulibaly, Y., Keita, M., Diango, D.M. and Diallo, G. (2011) Occlusions du grêle sur brides et adhérences en chirurgie générale CHU Gabriel Touré. Mali Médical, 26, 12-15.

[5] Schwenter, F., Dominguez, S., Meier, R., Saussure, W.O., Gervaz, P., Morel, P. and Platon, A. (2011) Occlusion grêle aiguë: traitement conservateur ou chirurgical? Revue Médicale Suisse, 7, 1341-1347.

[6] Arnaud, F.K., Chrystelle, V., Lionel, P., Franck, L., Caroline, S., et al. (2012) Epidémiologie de l'invagination intestinale aiguë chez l'enfant de moins de 1 an. Résultats préliminaires de l'étude Epistudy. $B E H, 10,138-143$.

[7] Buettcher, M., Baer, G., Bonhoeffer, J., Schaad, U.B. and Heininger, U. (2007) Three-year surveillance of intussusception in children in Switzerland. Pediatrics, 120, 473-480. https://doi.org/10.1542/peds.2007-0035

[8] Dieng, M., Cissé, M., Sanou, A., et al. (2010) Résultats à court terme des laparotomies itératives pour occlusion intestinale post opératoire. Journal Africain de chirurgie, $1,25-28$.

[9] Johannet, H., Traxer, O., Manceau, C., et al. (1999) Occlusion aigue du grêle sur Brides: Indications et résultats. Annales de Chirurgie, 53, 859-864. 